\title{
Ripe banana flour as a source of antioxidants in layer and sponge cakes
}

Cristina Segundo ${ }^{\mathbf{a}, \mathbf{b}}$, Laura Román ${ }^{\mathbf{b}}$, Manuel Lobo ${ }^{\mathbf{a}}$, Mario M. Martinez ${ }^{\mathbf{b}, \mathbf{c}}$, Manuel Gómez ${ }^{\mathbf{b}}$

${ }^{a}$ Facultad de Ingeniería, CIT Jujuy, Universidad nacional de Jujuy, CONYCET, Avenida Italo Palanca, 4600 Jujuy, Argentina

${ }^{\mathrm{b}}$ Food Technology Area. College of Agricultural Engineering. University of Valladolid, 34004 Palencia, Spain.

${ }^{\mathrm{c}}$ Whistler Center for Carbohydrate Research, Department of Food Science, Purdue University, West Lafayette, IN 47907, U.S.A.

\begin{abstract}
About one-fifth of all bananas harvested become culls that are normally disposed of improperly. However, ripe banana pulp contains significant amounts of fibre and polyphenol compounds as well as a high content of simple sugars $(61.06 \mathrm{~g} / 100 \mathrm{~g})$, making it suitable for sucrose replacement in bakery products. This work studied the feasibility of incorporating ripe banana flour $(20$ and $40 \%$ of replacement) in cake formulation. Physical, nutritional and sensory attributes of sponge and layer cakes were evaluated. The inclusion of ripe banana flour generally led to an increased batter consistency that hindered cake expansion, resulting in a slightly lower specific volume and higher hardness. This effect was minimised in layer cakes where differences in volume were only evident with the higher level of replacement. The lower volume and higher hardness contributed to the decline of the acceptability observed in the sensory test. Unlike physical attributes, the banana flour inclusion significantly improved the nutritional properties of the cakes, bringing about an enhancement in dietary fibre, polyphenols and antioxidant capacity (up to a threefold improvement in antioxidant capacity performance). Therefore, results showed that sugar replacement by ripe banana flour enhanced the nutritional properties of cakes, but attention should be paid to its inclusion level.
\end{abstract}

Keywords: cake, ripe banana, polyphenols, antioxidant capacity 


\section{Introduction}

The fruit obtained from banana trees is one of the most consumed tropical fruits in the world. The global production of banana in 2014 was $10.4 \times 107$ tons [1]. Since in the producer countries the loss of a part of the annual harvest is common (about one-fifth of all bananas harvested become culls) due to a lack of adequate infrastructure and poor marketing new uses for the banana fruit need to be investigated to reduce the waste it generates [2]. The flour obtained from green banana is rich in starch (61-76.5\%) and fibre (6-15.5\%) while it presents a low protein (less than 4\%) and lipid (less than $1 \%$ ) content [3]. In green banana flour, soluble sugars are presented in small amounts $(1.81 \%)$ and most of the total starch consists of resistant starch, with available starch only accounting for a low percentage $(\sim 36.18 \%)$ [4]. Meanwhile, as the banana ripening process takes place there is an increase in sugars [5] as well as in protein content, and a decrease in starch fraction [6]. Ripe banana is also rich in fructooligosaccharides [7], potassium, polyphenols, as catechin and tannins, and demonstrates an important antioxidant activity [8,9]. Experimental studies support a role of polyphenols in the prevention of cardiovascular diseases, cancers, neurodegenerative diseases, or diabetes [10].

Several studies have been done on the application of green banana flour to the production of bakery products [11-14]. However, studies on the application of ripe banana flour are scarce and limited to its inclusion in the formulation of gluten-free breads [15]. The high content of simple sugars in ripe banana flour could make this flour suitable for sugar replacement in some bakery products. In the case of cakes, sugar has a multiple function, acting as a sweetener but also being involved in the formation of the emulsion structure which can increase the gelatinisation temperature of starch, allowing the increase in the volume of the products. Sugar is also involved in Maillard reactions and caramelisation, changing the external colour of the cake [16].

In this way, our hypothesis was that the use of flour obtained from ripe bananas could: (1) demonstrate a similar functionality to sucrose in cake making while improving its nutritional properties with the inclusion of non-starch polysaccharides and polyphenols and; (2) minimise the waste of banana culls. Therefore, the aim of this research was to study the effect of ripe banana flour as a sucrose replacement in layer and sponge cakes. The characteristics of the batter in terms of batter density and rheology were determined. The quality of the final cakes was also evaluated in terms of specific volume, texture, dietary fibre, polyphenol content, antioxidant capacity, and acceptability.

\section{Materials and methods}

\section{Materials}

Wheat flour was supplied by Harinera la Castellana S.A (Medina de Campo, Valladolid, Spain) whilst sugar, sunflower oil, whole liquid milk, powdered milk and liquid pasteurized egg were purchased from the local market. The baking powder " $2 \mathrm{x} 1$ " and the emulsifier "SuperMixo T500" were provided by Puratos (Gerona, Spain). Bananas (Musa Cavendish var Nanica) were purchased ripe (state 7: yellow with black spots) [17]. 


\section{Methods}

\section{Processing of banana flour from ripe bananas}

Ripe bananas were peeled and ground in a Liliana AM523 juicer (Cheffy, Argentina) at 1 speed for 3 min. The paste obtained was placed in a tray and dried in an oven with forced convective flow at 60 ${ }^{\circ} \mathrm{C}$ for $48 \mathrm{~h}$. The dried paste was ground in a Numak FW 100 laboratory mill (Ojalvo, Argentina). This flour was sift in a Bühler MLI 300B siever (Uzwil, Switzerland) for 15 min and the fraction with particle size under $80 \mu \mathrm{m}$ was selected and stored in sealed plastic bags.

\section{Proximate analysis of banana flour}

Ripe banana flour had the following composition (wet basis): $11.53 \mathrm{~g} / 100 \mathrm{~g}$ of moisture content, $3.76 \mathrm{~g} / 100 \mathrm{~g}$ of protein, $3.05 \mathrm{~g} / 100 \mathrm{~g}$ of ash, $0.65 \mathrm{~g} / 100 \mathrm{~g}$ of lipids and $81.01 \mathrm{~g} / 100 \mathrm{~g}$ of carbohydrates, of which $61.06 \mathrm{~g} / 100 \mathrm{~g}$ are simple sugars (glucose, fructose, sucrose and maltose) and $6.59 \mathrm{~g} / 100 \mathrm{~g}$ are fibre $(5.24 \mathrm{~g} / 100 \mathrm{~g}$ of each is insoluble fibre). Total phenolic compounds were $283.90 \mathrm{mg}$ GA/100g flour. Banana flour was characterised following AACC [18] methods for moisture content (44.15.02), proteins (46.11.02), lipids (30.25.01), dietary fibre (32.05.01) and ash (08.12.01). Carbohydrates content was obtained by weight difference with the other flour components. Simple sugars content were measured by HPAEC-PAD method [19]. Phenolic compounds were determined following the method described in 2.2.6 section.

\section{Cake making}

Two kinds of cake, layer cake and sponge cake, were made. Layer cakes had the following formula: $350 \mathrm{~g}$ flour, $315 \mathrm{~g}$ sucrose, $210 \mathrm{~g}$ whole milk, $175 \mathrm{~g}$ liquid pasteurized egg, $105 \mathrm{~g}$ sunflower oil and $10.5 \mathrm{~g}$ baking powder. All ingredients were mixed in the Kitchen-Aid Professional mixer KPM5 (St. Joseph, Michigan, USA) for $1 \mathrm{~min}$ at speed 4 and $9 \mathrm{~min}$ at speed 6. Cake batter (185g) was placed into disposable oil-coated aluminium pans $(109 \times 159 \times 38 \mathrm{~mm})$ and the cakes were baked in an electric oven for $25 \mathrm{~min}$ at $185^{\circ} \mathrm{C}$. The sponge cake formula was as follows: $245 \mathrm{~g}$ flour, $240.5 \mathrm{~g}$ sucrose, $344 \mathrm{~g}$ liquid pasteurised egg, $55 \mathrm{~g}$ water, $14 \mathrm{~g}$ emulsifier, and $25 \mathrm{~g}$ powdered milk. A creaming-mixing procedure was used. All ingredients, except for the flour and milk, were mixed for 2 min at speed 6 using the Kitchen-Aid Professional mixer KPM5. After the addition of the milk and flour, the mixing process was continued for $3 \mathrm{~min}$ at speed 8 . Cake batter (125 g) was placed into oil-coated aluminium pans and baked as above.

After baking, the cakes were removed from the pans and left to cool for $60 \mathrm{~min}$ before being placed in coded plastic bags that were sealed to prevent them from drying. For each type of cake, layer or sponge, three formulations, performed in duplicate, were obtained. A control cake for each type of cake with the total sucrose content was made, (i.e., $315 \mathrm{~g}$ and $240.5 \mathrm{~g}$ of sucrose for layer and sponge cakes, respectively). For these layer and sponge cakes, sucrose was substituted by ripe banana flour at levels of $20 \%$ and $40 \%$ (named as S20 and S40, respectively).

\section{Batter measurements}

All the analyses performed on the batter were carried out in duplicate immediately after mixing the batters. Batter density was determined with a standard container $(100 \mathrm{cc})$ of known weight filled with batter. Rheological measurements were performed with a rheometer (Haake RheoStress 1, Thermo Fischer Scientific, Scheverte, Germany). Shear stress versus shear rate data were recorded using a concentric cylinder geometry programmed to increase the shear rate from 1 to $100 \mathrm{~s}^{-1}$ for 
$400 \mathrm{~s}$ (up curve), then to maintain this shear rate for $300 \mathrm{~s}$ and immediately followed by a reduction from 100 to $1 \mathrm{~s}^{-1}$ for $100 \mathrm{~s}$ (down curve). Data from the up curve of the shear cycle were fitted to Ostwald-de Waele model $\left(\sigma=\mathrm{K} \cdot \gamma^{\mathrm{n}}\right)$, where $\sigma$ is the shear stress $(\mathrm{Pa}), \gamma$ is the shear rate $\left(\mathrm{s}^{-1}\right), \mathrm{K}$ is the consistency coefficient $\left(\mathrm{Pa} \cdot \mathrm{s}^{\mathrm{n}}\right)$, and $\mathrm{n}$ is the flow behaviour index.

\section{Cake characteristics}

Cake characteristics were analysed 24 hours after baking. Cake volume was determined with the Volscan Profiler volume analyser (Stable Mycrosystems, Surrey, UK). The cake-specific volume was calculated as the ratio between the volume of the cake and its weight. Measurements were run in duplicate. Crumb texture was determined using a TA-XT2 texture analyser (Stable Microsystems, Surrey, UK). A 25-mm-diameter cylindrical aluminium probe was used in a 'texture profile analysis' (TPA) double compression test to penetrate to $50 \%$ depth, with a test speed of $2 \mathrm{~mm} / \mathrm{s}$ and a $30 \mathrm{~s}$ delay between the first and second compressions. Hardness $(\mathrm{N})$, cohesiveness and springiness were obtained from the TPA graphic. Measurements were made on two central slices (20mm thickness) from two cakes for each formulation.

Hedonic sensory evaluation of cakes was conducted with 72 volunteers, regular cake eaters, between 18-64 years of age and from various socioeconomic backgrounds. Cakes were evaluated one day after baking on the basis of acceptance of their appearance, odour, taste, texture, and overall liking on a nine-point hedonic scale. The scale of values ranged from "extremely like" to "extremely dislike" corresponding these scores to "9" and " 1 " respectively.

\section{Phenolic content}

Phenolic compounds were extracted with methanol-water acidified with $\mathrm{HCl}$ (50:50 v/v, pH 2, 50 $\mathrm{mL} \mathrm{g}^{-1}$ sample, $\left.16 \mathrm{~h}\right)$ and acetone-water $\left(70: 30 \mathrm{v} / \mathrm{v}, 50 \mathrm{~mL} \mathrm{~g}^{-1}\right.$ sample, $\left.60 \mathrm{~min}\right)$ at room temperature $\left(25^{\circ} \mathrm{C}\right)$ under constant stirring. After centrifugation $\left(15 \mathrm{~min}, 25^{\circ} \mathrm{C}, 3000 \times \mathrm{g}\right)$, supernatants were pooled and used to determine extractable polyphenols content and antioxidant capacity. Extractable polyphenols were determined by the Folin-Ciocalteu procedure [20]. Determination was performed at a wavelength of $765 \mathrm{~nm}$ in a spectrophotometer (UV/VIS Spectronic 4001/4, Spectronic Instrument, USA), and total polyphenol content was expressed as $\mathrm{mg}$ of gallic acid equivalents (GA)/100g dry matter. All analyses were carried out in duplicate.

\section{Free radical-scavenging assay (DPPH)}

The antioxidant activity of the extracts of the cakes was determined by DPPH free radical elimination. Three aliquots $(100,300$ and $500 \mu \mathrm{l})$ of each sample extract were taken and added to 3 $\mathrm{mL}$ of methanolic DPPH solution. The decrease in absorbance at $517 \mathrm{~nm}$ was determined spectrophotometrically during 300seg. The inhibition activity of the DPPH radical by the samples was calculated according to the equation 1.

Inhibition activity $(\%)=100 \times\left(1-\left(\mathrm{A}_{\mathrm{ss}} / \mathrm{A}_{0}\right)\right)$

where $A_{s s}$ is the absorbance of the solution in a steady state and $A_{0}$ is the absorbance of DPPH without the sample.

$\mathrm{IC}_{50}$ value $(\mathrm{mg}$ extract $/ \mathrm{ml})$ is the effective concentration at which the antioxidant activity was $50 \%$, i.e., the amount of sample required for $50 \%$ of free radical scavenging activity. $\mathrm{IC}_{50}$ value was obtained by interpolation from linear regression analysis. Each antioxidant attribute of ethanolic extracts from cakes was averaged out from two replications. 


\section{Statistical analysis}

Analysis of variance was used to study the differences between batters and cakes. Fisher's least significant difference (LSD) test was used to describe means with 95\% confidence. The analysis was carried out with Statgraphics PlusV5.1 software (Statpoint Technologies, Warrenton, USA).

\section{Results and Discussion}

\section{Batters characteristics}

The properties of batters are summarized in Table 1. Results showed that for sponge batters, when sucrose was replaced by ripe banana flour, an increase in density was accompanied by an increase in consistency $(\mathrm{K})$ as well as by a stronger pseudoplastic behaviour (lower flow behaviour index, $\mathrm{n}$ ), especially with the higher level of replacement. This stronger structure may be promoted by the water-binding capacity of the ripe banana flour components and related, in particular, to their carbohydrates composition (see section 2.2.2). Added to simple sugars, these carbohydrates are composed of a small amount of starch and fibre, mainly insoluble, which increases with the maturation of the banana [21]. In this way, Gómez et al. [22] already found that insoluble fibre incorporation incremented the consistency and decreased the $\mathrm{n}$ value of the batters. In this sense, higher batter consistency may reduce the movement of the air bubbles and avoids the coalescence phenomena, generating batters with a structure of smaller bubbles [23].

Contrary to the results for sponge cakes, in layer cakes, replacement of sucrose by ripe banana flour improved the air incorporation by reducing the batter density, which, in turn, modified the rheological properties, increasing the consistency and pseudoplastic character. Such modifications, as previously reported for sponge batters, can be related to the presence of carbohydrates different to simple sugars, but the higher air incorporation in the batter may also influence these results. In actual fact, Chesterton et al. [24] reported that the viscosity increased as the air content was enhanced in the batter. In general, a high consistency is related to a high capacity of batters to retain air, resulting in a high volume of the cakes. However, the increase of $\mathrm{K}$ should be achieved considering that a very high consistency could also diminish cake quality since it would impede the correct batter dosing and air expansion [14]. Differences between both types of cakes may be related to the greater air incorporation in form of small bubbles and to the lack of a superficial oil film able to stabilize these bubbles in sponge cakes [25]. Therefore, the structure in sponge cakes compared with that of layer cakes is more sensitive to changes in the ingredients or processing.

\section{Cake characteristics}

In order to assess the effect of ripe banana flour incorporation on the physical properties of cakes, specific volume and crumb texture were analysed (Table 1). The sucrose replacement by ripe banana flour, for sponge cakes, slightly reduced the specific volume. Yang and Foegeding [23] reported the importance of sucrose in obtaining appropriate volumes in angel cakes. Furthermore, it is common knowledge that sugars play a pivotal role in delaying starch gelatinisation, allowing for a greater expansion during cooking [16]. In our study, the greater consistency in batters made with ripe banana flour could have hampered the expansion of the air bubbles, negatively affecting the final volume of the cake.

Regarding textural properties of sponge cakes, crumb hardness was increased as the level of inclusion of ripe banana was greater. A negative relationship, therefore, between hardness and the 
specific volume of the cakes can be seen, which agrees with observations in other studies [22, 26]. The replacement of sugar by ripe banana flour reduced the cohesiveness, although no effect on the springiness of the cakes was noticed. This lower cohesiveness may be related to the fibre content, and especially insoluble fibre, found for ripe banana flour. Actually, a reduction in cohesiveness was also reported when incorporating fibres in other cakes [27]. The more limited amount of free water in banana cakes may impede intermolecular interaction among ingredients, increasing the susceptibility of cake crumb to fracture or crumble.

In layer cakes, the substitution of sugar at a level of $20 \%$ promoted a slight increase in the specific volume of the cakes, which may be explained by a better air incorporation in the batter (i.e., lower density). Conversely, when the level of sugar reduction was higher (40\%) a decrease in the specific volume occurred. In the batters made with banana flour inclusion the air incorporation was slightly higher which could increase the specific volume. However, an excessive increase in consistency may have also hindered the cakes expansion during baking.

Considering the hardness, this parameter also seems to be correlated to the specific volume, with the cakes with the lower volume being harder. Nevertheless, this trend is not followed by the cake made with $20 \%$ banana substitution, which had a hardness value higher compared to the control despite its higher volume. Previous studies [22, 26] have already proven that the correlation between hardness and volume is more significant in sponge than in layer cakes. Then, this trend for ripe banana cakes should be related to structural changes in the crumb, as shown in Figure 1, possibly influenced by the different effect on starch gelatinisation and retrogradation behaviour of sucrose and the simple sugars (mainly glucose and maltose) found in banana flour as well as to its additional fibre content. The effect on the springiness and cohesiveness is similar to that previously indicated on sponge cakes, where the inclusion of ripe banana decreased the cohesiveness, but without affecting the springiness.

According to the results, sponge and layer cakes with the inclusion of ripe banana generally led to a decline in the specific volume and hardness compared to the control, but it is important to highlight that, as Figure 1 demonstrates, all cakes presented an acceptable final volume, with no collapse in the height being visible. In Figure 1 the different colour of the cakes can also be noted. Changes found in the colour of the crumb and crust are similar for sponge and layer cakes, with darker crumbs and crusts as ripe banana flour is incorporated. These changes should be explained by the darker colour of banana flour resulted from the browning, suffered during the drying process of these flours.

The sensory analysis (Table 2) was performed in layer and sponge cakes with the highest ripe banana incorporation. The inclusion of banana flour led to a decline in overall acceptability of the cakes. This reduction in the acceptability was mainly due to differences in the odour and taste of the cakes made with ripe banana flour. This seems logical accounting that consumers are used to a certain flavour, and the inclusion of strange ingredients in the formula tends to reduce the acceptability. For layer cakes, the volume reduction and the increased hardness with the use of banana flour resulted in a higher decline in appearance and texture valuation compared to sponge cakes. Nonetheless, some of the tasters expressed preferences for cakes made with ripe banana, so this product could be marketed towards a niche market. 


\section{Dietary fibre, phenolic compounds and antioxidant capacity}

Dietary fibre, phenolic compounds and antioxidant capacity were analysed for layer and sponge cakes (Table 3). In both types of cakes an increase in dietary fibre was observed when sucrose was replaced by ripe banana flour according to the fibre content of the banana flour $(6.59 \mathrm{~g} / 100 \mathrm{~g})$. In particular, these fibres would include pectin, cellulose, lignin and hemicellulose, typically found in banana flours [28]. For layer and especially sponge cakes, a significant increase of the polyphenol content was observed when increasing the amount of ripe banana flours in the formula, which is also consistent with the high polyphenol content of the initial flour (283.90 mg GA/100g flour). Banana flour contains high amount of phenolic compounds such as catequin, epicatequin, lignin, anthocyanin and tannin with antioxidant capacities [9, 29]. The higher increase in polyphenol content observed for sponge cakes compared to layer counterparts can be related to the different effect of the matrix on preserving those components. In sponge cakes, the low density of their batters, indicating a greater number of bubbles with smaller size, could bring about a more stable (i.e, less coalescence) and faster expansion of the batter in the oven (see higher specific volume in Table 1) which can lead to moderating the mass and heat transfers in the cake diminishing the loss of phenolic compounds during baking. This observation was already seen by Segundo et al. [14] when preparing sponge and layer cakes with green banana flour. Furthermore, the higher phenolic compounds can be associated with the presence of dietary fibre in the banana flour since dietary fibre can bind polyphenols retaining them during cake processing and contributing to the increase in the final cake. The interactions between polyphenols and fibres can occur as soon as polyphenols come into contact with plant cell wall analogues such as cellulose or cellulose/pectin [30], which are present in ripe banana flour. Polyphenols can increase the scavenging activity of the stable DPPH radical model, as a consequence of the hydrogen donating ability [31]. In this way, the addition of ripe banana flours also led to sponge and layer cakes with lower values of $\mathrm{IC}_{50}$, i.e., lower effective concentration at which the antioxidant activity was $50 \%$, indicating higher phytochemical activity. It is noteworthy that the improvement in the antioxidant capacity was more than threefold higher compared to the control.

\section{Conclusion}

In this study, it is shown that the use of banana flour obtained from ripe banana can improve the nutritional properties of cakes bringing about a reduction in the total amount of sugars ( $40 \%$ lower) and an enhancement of the phenolic compounds compared to the control. The significant antioxidant capacity of cakes substituted with ripe banana flour is an additional nutraceutical characteristic to that of the lower content in simple sugars. Then, consumption of these cakes could give more beneficial effects to people's health. Nevertheless, attention should be paid to the level of sucrose replacement used, accounting for the fact that the physicochemical hardness and specific volume of the cakes can be worsened with the use of ripe banana.

\section{Acknowledgements}

The authors acknowledge the financial support of the Spanish Ministry of Economy and Competitiveness (Project AGL2014-52928-C2-2-R) and the European Regional Development Fund (FEDER). Laura Roman would like to acknowledge the University of Valladolid for her predoctoral scholarship. 


\section{References}

[1] FAO (2017). FAOSTAT. <http://faostat3.fao.org>.

[2] Zhang P, Whister RL, BeMiller J, Hamaker BR (2005) Banana starch: Production, physicochemical properties, and digestibility - A review. Carbohydr Polym 59:443-458

[3] Da Mota RV, Lajolo FM, Ciacco C, Cordenunsi BR (2000) Composition and functional properties of banana flour from different varieties. Starch/Starke 52:63-68

[4] Menezes EW, Tadini CC, Tribess TB, Zuleta A, Binaghi J, Pak N, Vera, G, Dan MCT, Bertolini AC, Cordenunsi BR, Lajolo FM (2011) Chemical composition and nutritional value of unripe banana flour (Musa acuminata, var. Nanicão). Plant Foods Hum Nutr 66:231-237

[5] Offem JO, Thomas OO (1993) Chemical changes in relation to mode and degree of maturation of plantain (Musa paradisiaca) and banana (Musa sapientum) fruits. Food Res Int 26:187-193

[6] Ayo-Omogie HN, Adeyemi IA, Otunola ET (2010) Effect of ripening on some physicochemical properties of cooking banana (Musa $A B B$ Cardaba) pulp and flour. Int J Food Sci Technol 45:26052611

[7] Der Agopian RG, Soares CA, Purgato E, Cordenunsi BR, Lajolo FM. (2008) Identification of fructooligosaccharides in different banana cultivars. J Agr Food Chem 56:3305-3310

[8] Anyasi TA, Jideani AIO, Mchau GRA (2015) Effect of organic acid pretreatment on some physical, functional and antioxidant properties of flour obtained from three unripe banana cultivars. Food Chem 172:515-522

[9] Sulaiman SF, Yusoff NA, Eldeen IM, Seow EM, Sajak AAB, Supriatno, Ooi KL (2011) Correlation between total phenolic and mineral contents with antioxidant activity of eight Malaysian bananas (Musa sp.). J Food Comp Anal 24:1-10

[10] Scalbert A, Manach C, Morand C, Remesy C, Jimenez L (2005) Dietary polyphenols and the prevention of diseases. Crit Rev Food Sci Nutr 45:287-306

[11] Agama-Acevedo E, Islas-Hernández JJ, Pacheco-Vargas G, Osorio-Díaz P, Bello-Pérez LA (2012) Starch digestibility and glycemic index of cookies partially substituted with unripe banana flour. LWT - Food Sci Technol 46:177-182

[12] Ho LH, Aziah Abdul AN, Azahari B (2013) Physico-chemical characteristics and sensory evaluation of wheat bread partially substituted with banana (Musa acuminata X balbisiana cv. Awak) pseudostem flour. Food Chem 139:532-539

[13] Juarez-Garcia E, Agama-Acevedo E, Sáyago-Ayerdi SG, Rodríguez-Ambriz SL, Bello-Pérez LA (2006) Composition, digestibility and application in breadmaking of banana flour. Plant Foods Hum Nutr 61:131-137

[14] Segundo C, Román L, Gómez M, Martínez MM (2017) Mechanically fractionated flour isolated from green bananas ( $M$. cavendishii var. nanica) as a tool to increase the dietary fiber and phytochemical bioactivity of layer and sponge cakes. Food Chem 219:240-248

[15] Seguchi M, Tabara A, Kyoko I, Takeuchi M, Nakamura C (2014) Development of gluten-free bread baked with banana (Musa spp.) flour. Food Sci Technol Res 20:1-7

[16] Wilderjans E, Luyts A, Brijs K, Delcour JA (2013) Ingredient functionality in batter type cake making. Trends Food Sci Technol 30:6-15 
[17] De Costa DM, Gunawardhana HMDM (2012) Effects of sodium bicarbonate on pathogenicity of Colletotrichum musae and potential for controlling postharvest diseases of banana. Postharvest Biol Technol 68:54-63

[18] AACC (2016) Approved methods of the American Association of Cereal Chemists. American Association of Cereal Chemists, St. Paul, Minnesota

[19] Pico J, Martínez MM, Martín MT, Gómez M (2015) Quantification of sugars in wheat flours with an HPAEC-PAD method. Food Chem 173:674-681

[20] Singleton VL, Orthofer R, Lamuela-Raventos RM (1999) Analysis of total phenols and other oxidation substrates and antioxidants by means of Foline Ciocalteu reagent. Methods Enzymol 299:152-178

[21] Emaga TH, Andrianaivo RH, Wathelet B, Tchango JT, Paquot M (2007) Effects of the stage of maturation and varieties on the chemical composition of banana and plantain peels. Food Chem 103:590-600

[22] Gómez M, Ruiz-Paris E, Oliete B, Pando V (2010) Modelling of texture evolution of cakes during storage. J Text Stud 41:17-33

[23] Yang X, Foegeding EA (2010) Effects of sucrose on egg white protein and whey protein isolate foams: Factors determining properties of wet and dry foams (cakes). Food Hydrocolloids 24:227238

[24] Chesterton AKS, Meza BE, Moggridge GD, Sadd PA, Wilson DI (2011) Rheological characterisation of cake batters generated by planetary mixing: Elastic versus viscous effects. J Food Eng 105:332-342

[25] de la Hera E, Martinez M, Oliete B, Gómez M (2013) Influence of flour particle size on quality of gluten-free rice cakes. Food Bioprocess Technol 6:2280-2288

[26] de la Hera E, Oliete B, Gómez M (2013) Batter characteristics and quality of cakes made with wheat-oats flour blends. J Food Qual 36:146-153

[27] Gómez M, Moraleja A, Oliete B, Caballero P (2010) Effect of fibre size on the quality of fibreenriched layer cakes. LWT-Food Sci Technol 43:33-38

[28] Thebaudin JY, Lefebvre AC, Harrington M, Bourgeois CM (1997) Dietary fibres: Nutritional and technological interest. Trends Food Sci Technol 8:41-48

[29] Fatemeh SR, Saifullah R, Abbas FMA, Azhar ME (2012) Total phenolics, flavonoids and antioxidant activity of banana pulp and peel flours: influence of variety and stage of ripeness. Int Food Res J 19:1041-1046

[30] Padayachee A, Netzel G, Netzel M, Day L, Zabaras D, Mikkelsen D, Gidley MJ (2012) Binding of polyphenols to plant cell wall analogues-Part 2: Phenolic acids. Food Chem 135:2287-2292

[31] Von Gadow A, Joubert E, Hannsman CF (1997) Comparison of the antioxidant activity of aspalathin with that of other plant phenols of rooibos tea (Aspalathus linearis), $\alpha$-tocopherol, BHT, and BHA. J Agr Food Chem 45:632-638 
Table 1. Physical properties of sponge and layer batters and cakes with reduced sugar content

\begin{tabular}{|c|c|c|c|c|c|c|c|}
\hline & \multicolumn{3}{|c|}{ Batters } & \multicolumn{4}{|c|}{ Cakes } \\
\hline & $\varrho\left(\mathrm{g} / \mathrm{cm}^{3}\right)$ & $\begin{array}{c}\mathrm{K} \\
\left(\mathrm{Pa} \mathrm{s}^{\mathrm{n}}\right)\end{array}$ & $\mathrm{n}$ & $\begin{array}{c}\text { Specific volume } \\
\left(\mathrm{cm}^{3} / \mathrm{g}\right)\end{array}$ & $\begin{array}{l}\text { Hardness } \\
\text { (N) }\end{array}$ & Springiness & Cohesiveness \\
\hline \multicolumn{8}{|c|}{ Sponge cakes } \\
\hline Control & $0.38 \mathrm{a}$ & $44 \mathrm{a}$ & $0.51 \mathrm{c}$ & $4.27 \mathrm{~b}$ & $3.04 \mathrm{a}$ & $0.86 a$ & $0.65 b$ \\
\hline S20 & $0.40 \mathrm{a}$ & $57 \mathrm{~b}$ & $0.43 b$ & $3.93 a$ & $4.41 \mathrm{~b}$ & $0.91 \mathrm{a}$ & $0.60 \mathrm{a}$ \\
\hline S40 & $0.43 b$ & $98 \mathrm{c}$ & $0.22 \mathrm{a}$ & $3.89 \mathrm{a}$ & $5.67 \mathrm{c}$ & $0.89 \mathrm{a}$ & $0.62 \mathrm{a}$ \\
\hline \multicolumn{8}{|c|}{ Layer cakes } \\
\hline Control & $1.11 \mathrm{~b}$ & $22 \mathrm{a}$ & $0.61 \mathrm{c}$ & $2.13 \mathrm{~b}$ & $5.35 \mathrm{a}$ & $0.88 \mathrm{a}$ & $0.61 \mathrm{c}$ \\
\hline S20 & $1.06 \mathrm{a}$ & $77 \mathrm{~b}$ & $0.42 \mathrm{~b}$ & $2.36 c$ & $6.60 \mathrm{~b}$ & $0.90 \mathrm{a}$ & $0.54 \mathrm{~b}$ \\
\hline $\mathrm{S} 40$ & $1.06 \mathrm{a}$ & $183 c$ & $0.28 \mathrm{a}$ & $1.79 \mathrm{a}$ & $14.55 c$ & $0.87 \mathrm{a}$ & $0.44 \mathrm{a}$ \\
\hline \multicolumn{8}{|c|}{$\begin{array}{l}\text { Mean values followed by the same letter in each column, for each cake, are not significantly different at } \mathrm{p} \leq 0.05 \text {. } \\
\text { S20 and S40: } 20 \% \text { and } 40 \% \text { sugar substitution by ripe banana flour, respectively. } \\
\varrho \text {, batter density; K, consistency coefficient; n, flow behaviour index. }\end{array}$} \\
\hline \multicolumn{8}{|c|}{ Table 2 . Sensory test of sponge and layer cakes with reduced sugar content } \\
\hline & \multicolumn{2}{|c|}{ Appearance } & Odour & Texture & Taste & \multicolumn{2}{|c|}{ Overall acceptability } \\
\hline \multicolumn{8}{|c|}{ Sponge cakes } \\
\hline Control & \multicolumn{2}{|c|}{$7.71 \mathrm{~b}$} & $7.32 \mathrm{~b}$ & $7.24 b$ & $7.49 \mathrm{~b}$ & \multicolumn{2}{|c|}{$7.65 b$} \\
\hline $\mathrm{S} 40$ & \multicolumn{2}{|c|}{$6.31 \mathrm{a}$} & $5.79 \mathrm{a}$ & $6.17 \mathrm{a}$ & $5.71 \mathrm{a}$ & \multicolumn{2}{|c|}{$5.64 a$} \\
\hline \multicolumn{8}{|c|}{ Layer cakes } \\
\hline Control & \multicolumn{2}{|c|}{$7.60 \mathrm{~b}$} & $7.07 \mathrm{~b}$ & $6.97 b$ & $7.18 \mathrm{~b}$ & \multicolumn{2}{|c|}{$7.38 \mathrm{~b}$} \\
\hline S40 & \multicolumn{2}{|c|}{$4.75 a$} & $5.26 \mathrm{a}$ & $4.61 \mathrm{a}$ & $4.89 \mathrm{a}$ & \multicolumn{2}{|c|}{$5.38 \mathrm{a}$} \\
\hline
\end{tabular}

Mean values followed by the same letter in each column, for each cake, are not significantly different at $\mathrm{p} \leq 0.05$.

S20 and S40: 20\% and 40\% sugar substitution by ripe banana flour, respectively

Table 3. Effect of ripe banana flour on the fibre and polyphenol content and IC50 of cakes Dietary fibre (\%) Polyphenol content (mg GA/100g) $\begin{gathered}\mathrm{IC50} \\ (\mathrm{mg} / \mathrm{mL})\end{gathered}$

$\begin{array}{cccc}\text { Sponge cakes } & & & \\ \text { Control } & 0.28 \mathrm{a} & 20.26 \mathrm{a} & 130.78 \mathrm{c} \\ \text { S20 } & 0.56 \mathrm{~b} & 49.08 \mathrm{~b} & 89.10 \mathrm{~b} \\ \text { S40 } & 0.81 \mathrm{c} & 77.70 \mathrm{c} & 62.23 \mathrm{a} \\ \text { Layer cakes } & & & 168.14 \mathrm{c} \\ \text { Control } & 0.34 \mathrm{a} & 31.51 \mathrm{a} & 36.55 \mathrm{a} \\ \text { S20 } & 0.64 \mathrm{~b} & 42.79 \mathrm{~b} & 45.1 \mathrm{~b} \\ \text { S40 } & 0.94 \mathrm{c} & 66.99 \mathrm{c} & \mathrm{c}\end{array}$

Mean values followed by the same letter in each column, for each cake, are not significantly different at $\mathrm{p} \leq 0.05$. S20 and S40: $20 \%$ and 40\% sugar substitution by ripe banana flour, respectively. IC50, amount of sample required for $50 \%$ of free radical scavenging activity. 

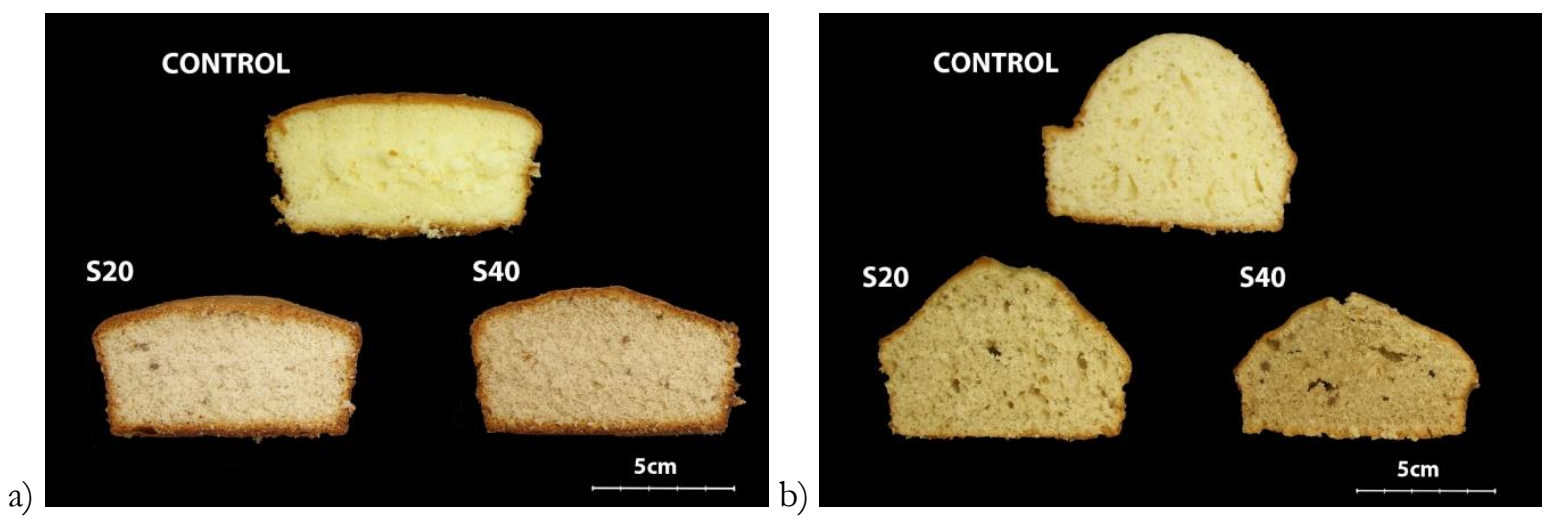

Figure 1. Cross-section of sponge (a) and layer cakes (b). S20 and S40: 20\% and 40\% sugar substitution by ripe banana flour, respectively. 